\title{
Severity of heterotopic ossification in patients following surgery for hip fracture: a retrospective observational study
}

Daichi Hayashi ${ }^{i^{*}}$ D, Elaine S. Gould ${ }^{1}$, Corey Ho ${ }^{1,2}$, Dennis L. Caruana ${ }^{3}$, David E. Komatsu ${ }^{4}$, Jie Yang ${ }^{5}$, Chencan Zhu ${ }^{6}$, Musa Mufti ${ }^{1}$ and James Nicholson ${ }^{4}$

\begin{abstract}
Background: Heterotopic ossification $(\mathrm{HO})$ is a relatively common complication following hip surgery treated with open reduction and internal fixation, total arthroplasty or hemiarthroplasty. Development of $\mathrm{HO}$ after hip surgery is an important clinical issue as it can affect functional status. We aimed to determine whether there was association between severity of heterotopic ossification about the hip and the interval between the time of hip fracture and surgery.

Materials and methods: Our retrospective study included 151 patients (age range 33-95 years) treated for hip fractures by hemiarthroplasty. Medical records were reviewed for time interval to surgery, laterality, surgical approach, and patient age. Patients who had any post-operative complications were excluded. Radiographs were semiquantitatively assessed for the degree of heterotopic ossification based on Brooker Classification (5-point scale). Statistical analysis was performed utilizing Chi-square, Kruskal-Wallis, and Score tests, and also a proportional odds model (significance level set at 0.05).

Results: Thirty eight patients had no heterotopic ossification, 43 had class 1, 55 had class 2, and 15 had class 3 or greater heterotopic ossification. The majority of patients (59.6\%) had surgery within 2 days of acute injury. Severe heterotopic ossification ( $\mathrm{HO}_{3}+$ ) was associated with the longer interval between the time of acute hip fracture and surgery (median 6 days) vs. median 2 days in all other groups ( $\mathrm{HO}$ classes $0-2)(p=0.0015)$. The odds ratio and $95 \%$ $\mathrm{Cl}$ for one level higher $\mathrm{HO}$ class was $1.296(1.152,1.459)$, which meant that the odds of having $\mathrm{HO}$ class one level higher increased by about $29.6 \%$ for every one-day increase in the days to surgery. No significant association was found for other variables.
\end{abstract}

Conclusion: Class 3 or greater $\mathrm{HO}$ was associated with longer time interval between time of acute hip fracture and surgery compared to all other groups (HO class 0-2).

Keywords: Hip, Arthroplasty, Postoperative complications, Orthopedic procedures, Radiography

\footnotetext{
* Correspondence: Daichi.Hayashi@stonybrookmedicine.edu

Author statement: Our work described in this manuscript was previously presented as an oral presentation at the Society of Skeletal Radiology $41^{\text {st }}$ Annual Meeting in 2018 in Texas, Austin, United States, March 25-28, 2018. Hayashi D, Ho C, Caruana D, Komatsu D, Nicholson J, Mufti M, Yang J, Zhu C, Gould E.

Association between severity of heterotopic ossification around the hip joint and the interval between the time of injury and surgery. Abstract Book, p.93

'Department of Radiology, Stony Brook Medicine, HSC 4-120, Stony Brook, NY 11794, USA

Full list of author information is available at the end of the article
}

(c) The Author(s). 2019 Open Access This article is distributed under the terms of the Creative Commons Attribution 4.0 International License (http://creativecommons.org/licenses/by/4.0/), which permits unrestricted use, distribution, and reproduction in any medium, provided you give appropriate credit to the original author(s) and the source, provide a link to the Creative Commons license, and indicate if changes were made. The Creative Commons Public Domain Dedication waiver (http://creativecommons.org/publicdomain/zero/1.0/) applies to the data made available in this article, unless otherwise stated. 


\section{Background}

Heterotopic ossification $(\mathrm{HO})$ is a relatively common complication following hip surgery treated with open reduction and internal fixation (ORIF), total arthroplasty (THA) or hemiarthroplasty. For example, a recent study showed the prevalence of $\mathrm{HO}$ after minimally invasive short-stem THA using a modified anterolateral approach to be $7.8 \%$ (16 out of 216 cases) [1]. Development of HO after hip surgery is an important clinical issue as it can affect functional status [2]. Means to prevent or reduce HO have been explored and include pre-operative [3] and post-operative irradiation [4] and the use of nonsteroidal anti-inflammatory drugs $[5,6]$. Rate and degree of $\mathrm{HO}$ after THA were shown to be affected by patient gender [7], surgical approach [8,9] as well as type of surgery [10]. Moreover, African-American ethnicity has been shown to be an independent risk factor for $\mathrm{HO}$ formation after THA [11]. An increased occurrence of $\mathrm{HO}$ was also reported specifically in patients with ankylosing spondylitis, elevated preoperative serum inflammatory markers and prolonged duration of surgery [12]. Previous hip $\mathrm{HO}$ formation and bilateral hypertrophic hip osteoarthritis are other known risk factors for $\mathrm{HO}$ [13].

HO shows progression over time in radiographic appearance. In early stage, it is typically a soft tissue mass without overt calcification and can often be missed. In the mineralization stage which can occur within 10 days after causative insult, calcification usually starts peripherally. Lesions can also be poorly organized without recognizable mineralization pattern. In mature $\mathrm{HO}$, cortical bone is formed. The degree of $\mathrm{HO}$ can be semiquantitatively assessed using the Brooker classification (grade 1-4) [14]. So far, the relationship between time of surgery and the severity of postoperative $\mathrm{HO}$ has not been well established in the literature. In a single center retrospective study, interval from injury to surgery was not statistically significantly associated with development and severity of $\mathrm{HO}$ in a cohort of 241 patients with acetabular fractures [15]. Another retrospective study showed that patients who underwent THA for acetabular fracture early after injury had higher (4-fold) chance of developing $\mathrm{HO}$ [16]. However, in other retrospective and prospective studies of $\mathrm{HO}$ after surgical repair of elbow fractures, longer time to surgery was an independent predictor of $\mathrm{HO}[17,18]$. Thus, the existing literature evidence on the relationship between time to surgery and the incidence/severity of $\mathrm{HO}$ remains controversial. We hypothesized that the longer the time to surgery after hip injury, the more severe the postoperative $\mathrm{HO}$ will become.

The aim of our study was to determine the association between severity of heterotopic ossification around the hip joint and the interval between the time of injury and surgery.

\section{Methods \\ Subjects}

Our retrospective study received Institutional Review Board approval and the need for informed consent from the patients was waived. We retrospectively reviewed the medical records in our institution for patients who had hip bipolar hemiarthroplasty (CPT codes 27125 and 27236) performed by an orthopedic surgeon to treat femoral neck fractures between 01/01/2003 and 11/22/ 2013. For each patient, the date of surgery, laterality (left or right hip), surgical approach (lateral, posterior, anterolateral), patient age, date of injury and interval between injury and surgery (days) were recorded. We excluded patients who had postoperative complications such as re-fracture, and hardware related complications including loosening, fracture and infection.

\section{Radiographic evaluation of heterotopic ossification}

Using post-operative radiographs of the pelvis/hip, the severity of post-operative heterotopic ossification was semiquantitatively graded using the Brooker classification as follows: class $1=$ islands of bone within the soft tissues about the hip; class $2=$ bone spurs from the pelvis or proximal end of the femur, leaving at least one centimeter between opposing bone surfaces; class $3=$ bone spurs from the pelvis or proximal end of the femur, reducing the space between opposing bone surfaces to less than one centimeter; class $4=$ apparent bone ankyloses of the hip (Fig. 1 and Table 1) [14]. Pelvis/hip radiographs were read in consensus by one attending musculoskeletal radiologist and one musculoskeletal radiology fellow blinded to clinical information. If a patient had more than one follow-up radiographs, the most recent radiograph was reviewed.

\section{Statistical analysis}

Since the number of subjects with HO class "3" and "4" were low ( $N=11$ and 4 , respectively), they were combined together as " $3+$ " in the following analysis. Chi-square tests with exact $P$-values based on Monte Carlo simulation were utilized to examine the marginal association between categorical variables (gender, approach, side) and $\mathrm{HO}$ class. Kruskal-Wallis tests were used to examine the marginal association between continuous variables (days to surgery, age) and $\mathrm{HO}$ class. Proportional odds model was used to further quantify the relationship between $\mathrm{HO}$ class (treated as ordinal variable) and days to surgery. Score test was utilized to confirm the proportional odds assumption. Of note, these additional analyses were not performed for other variables, since the results of the aforementioned Chi-squared test and Kruskal-Wallis test showed statistically non-significant association with the severity of $\mathrm{HO}$ with $p$-values well above 0.05 , and thus calculation of odds ratio would also be non-significant. Statistical analysis was 


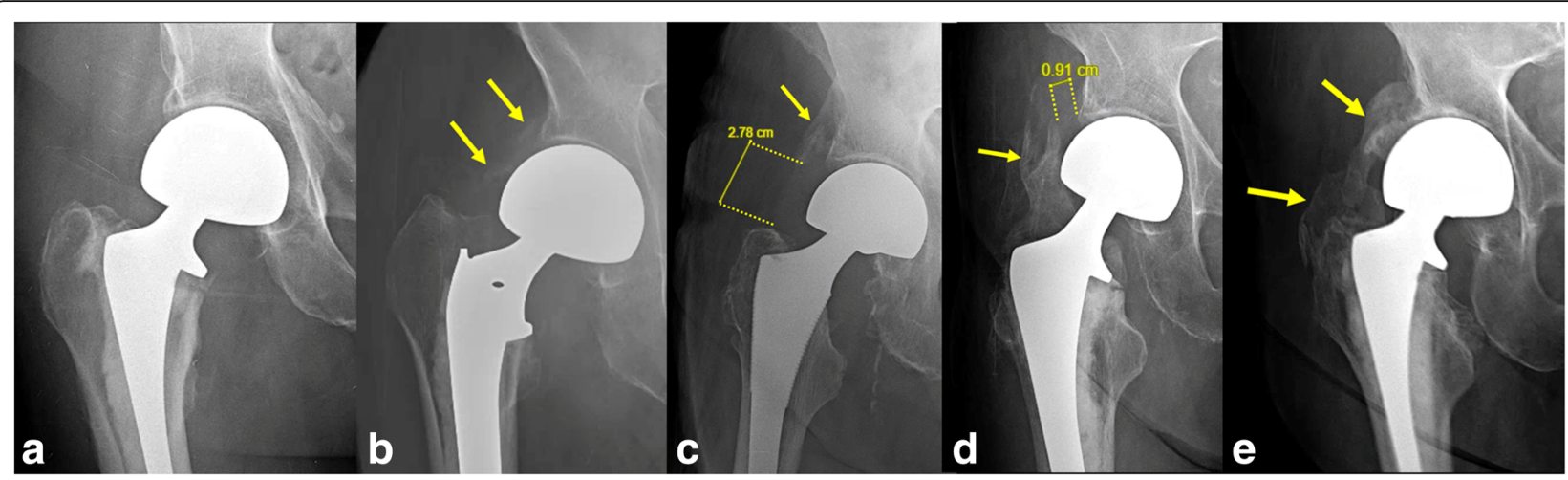

Fig. 1 Brooker classification of heterotopic ossification in the hip. a Class 0 - no heterotopic ossification is noted about the hip; $\mathbf{b}$ class 1 - small islands of soft tissue ossifications are noted about the hip (arrows); c class 2- a moderate spur (arrow) arising from the right acetabulum, leaving an osseous gap of greater than $1 \mathrm{~cm}$ measured from the greater trochanter; $\mathbf{d}$ class 3 - a very large spur (arrow) arising from the greater trochanter of the right proximal femur approaching the acetabulum, leaving an osseous gap of less than $1 \mathrm{~cm}$; e class 4 - arrows show large spurs arising from the acetabulum and also greater trochanter of the right proximal femur, resulting in ankylosis

performed using SAS 9.4 and significance level was set at 0.05 (SAS Institute Inc., Cary, NC).

\section{Evaluation of possible influence of time interval between the date of surgery and date of follow-up radiograph}

As we reviewed the obtained dataset, it became clear that there was a large variation in time interval between the date of surgery and date of follow-up radiograph (range 76-3049 days). One might therefore think patients who had longer interval for follow-up were more likely to have $\mathrm{HO}$. We therefore assessed the distribution of follow-up interval (in days) among different $\mathrm{HO}$ categories $(0,1,2,3+)$ and assessed if the duration of time interval between the date of surgery and follow-up radiograph affected the severity of $\mathrm{HO}$.

\section{Results}

Table 2 shows the descriptive table for patients' gender, age, days to surgery, surgery approach and side by $\mathrm{HO}$ class. Most of the patients were 65 years or older, but 18 patients younger than 65 years received bipolar hemiarthroplasty due to clinical indications such as delayed surgery secondary to compromised systemic status, poor general health that would prevent a second operation or displaced fracture which was several days old. Severe heterotopic ossification ( $\mathrm{HO} 3+$ ) was associated with the longer interval between the time of acute hip fracture and surgery (median 6 days) vs. median 2 days in all other groups ( $\mathrm{HO}$ classes $0-2)(p=0.0015)$. In other words, $\mathrm{HO}$ class 1 and $\mathrm{HO}$ class 2 had the same the interval between the time of acute hip fracture and surgery as patients without ossifications. Patient age did not significantly differ amongst different $\mathrm{HO}$ classes with a large range of overlap around the age $80(p=0.2812)$. Patient gender was also not associated with $\mathrm{HO}$ class $(p=0.0705)$ although higher proportion of male patients (compared to female patients) had HO class 2 (44.74\% vs. $33.63 \%)$ and class $3+(15.70 \%$ vs. $7.96 \%)$. Conversely, a higher proportion of female patients had HO class zero (30.09\% vs. 10.53\%) compared to men. Surgical approach and side of surgery showed essentially no association with $\mathrm{HO}$ class, with $p$-values much higher than 0.05 ( $p=0.1882$ for surgical approach, $p=0.7383$ for side of surgery). Figure 2 shows the distribution of subjects according to the number of days to surgery. A majority of patients (90 of 151, 59.6\%) had a surgical intervention within 2 days of presentation.

Proportional odds model was used to further analyze the relationship between $\mathrm{HO}$ class and time to surgery. The odds ratio and $95 \% \mathrm{CI}$ for one level higher $\mathrm{HO}$ class was 1.296 (1.152, 1.459), which means that the odds of having $\mathrm{HO}$ class one level higher increases by about $29.6 \%$ for every one-day increase in the days to surgery. This meant that as days to surgery increased, patients were more likely to have higher class of heterotopic ossification.

The median number of days between the surgery and follow-up radiograph was 321, with a range of 76-3049.

Table 1 Brooker classification of heterotopic ossification in the hip

\begin{tabular}{ll}
\hline Class & Definition \\
\hline 1 & Islands of bone within the soft tissues about the hip \\
3 & Bone spurs from the pelvis or proximal end of the femur, leaving at least 1 cm between opposing bone surfaces \\
4 & Bone spurs from the pelvis or proximal end of the femur, reducing the space between opposing bone surfaces to less than $1 \mathrm{~cm}$ \\
\hline
\end{tabular}


Table 2 Descriptive table for patients' characteristics and surgery information by $\mathrm{HO}$ class

\begin{tabular}{|c|c|c|c|c|c|c|c|}
\hline \multicolumn{2}{|l|}{ Variables } & Total $(N=151)$ & $\mathrm{HO}$ class $0(N=38)$ & $\mathrm{HO}$ class $1(N=43)$ & $\mathrm{HO}$ class $2(N=55)$ & $\mathrm{HO}$ class $3+(\mathrm{N}=15)$ & $P$-values \\
\hline \multicolumn{2}{|l|}{ Days to surgery } & $2 \pm 3$ & $2 \pm 1$ & $2 \pm 3$ & $2 \pm 3$ & $6 \pm 6$ & 0.0015 \\
\hline \multicolumn{2}{|l|}{ Age } & $81 \pm 11$ & $82.5 \pm 16$ & $83 \pm 11$ & $80 \pm 11$ & $77 \pm 10$ & 0.2812 \\
\hline \multirow[t]{2}{*}{ Gender } & Female & $113(74.83 \%)$ & 34 (30.09\%) & 32 (28.32\%) & 38 (33.63\%) & 9 (7.96\%) & \multirow[t]{2}{*}{0.0705} \\
\hline & Male & $38(25.17 \%)$ & $4(10.53 \%)$ & 11 (28.95\%) & $17(44.74 \%)$ & $6(15.79 \%)$ & \\
\hline \multirow[t]{3}{*}{ Surgical Approach } & Anterolateral & $4(2.65 \%)$ & $0(0.00 \%)$ & $3(75.00 \%)$ & $1(25.00 \%)$ & $0(0.00 \%)$ & \multirow[t]{3}{*}{0.1882} \\
\hline & Lateral & 33 (21.85\%) & $5(15.15 \%)$ & $8(24.24 \%)$ & $15(45.45 \%)$ & $5(15.15 \%)$ & \\
\hline & Posterior & $114(75.50 \%)$ & $33(28.95 \%)$ & 32 (28.07\%) & 39 (34.21\%) & $10(8.77 \%)$ & \\
\hline \multirow[t]{2}{*}{ Side of surgery } & Left & $82(54.30 \%)$ & $20(24.39 \%)$ & $24(29.27 \%)$ & $28(34.15 \%)$ & $10(12.20 \%)$ & \multirow[t]{2}{*}{0.7383} \\
\hline & Right & 69 (45.70\%) & $18(26.09 \%)$ & 19 (27.54\%) & 27 (39.13\%) & $5(7.25 \%)$ & \\
\hline
\end{tabular}

*For categorical variables, $p$-value was based on Chi-squared test with exact $p$-value from Monte Carlo simulation; for continuous variables, median $+/-$ interquartile range were reported and $p$-value was based on Kruskal-Wallis test

In our study sample, distribution of follow-up interval among different $\mathrm{HO}$ categories $(0,1,2,3+)$ was similar (Fig. 3) and longer follow-up interval did not necessarily correspond to higher $\mathrm{HO}$ category. The patient with longest follow-up interval (3049 days) had class $2 \mathrm{HO}$, and there was a patient who had no $\mathrm{HO}$ at 2746 days. Conversely, a patient whose follow-up radiograph was taken at 96 days had class $4 \mathrm{HO}$. When our sample was stratified according to $\mathrm{HO}$ class, the median follow-up interval for class 0 was 353.5 days (range, 89-2746); class 1 was 306 days (range, 76-2296); class 2 was 279 days (range, 94-3049); and class 3+ was 321 days (range, 95-2345). Thus, shortest median follow-up interval was observed with class $2 \mathrm{HO}$ group, and the median follow- up interval was actually shorter for class $3+$ group compared to class 0 group.

\section{Discussion}

Our results noted a strong association between the severity of postoperative $\mathrm{HO}$ and time to surgery. Available literature evidence regarding risk of postoperative $\mathrm{HO}$ and its association with time interval between injury and surgery has been mixed. No significant association between development/severity of $\mathrm{HO}$ and time interval from injury to surgery was found in d'Heurle et al's study in which hip fracture patients were evaluated [15], while Chemaly et al. reported patients who underwent 'early' surgery (total hip arthroplasty within 60 days of

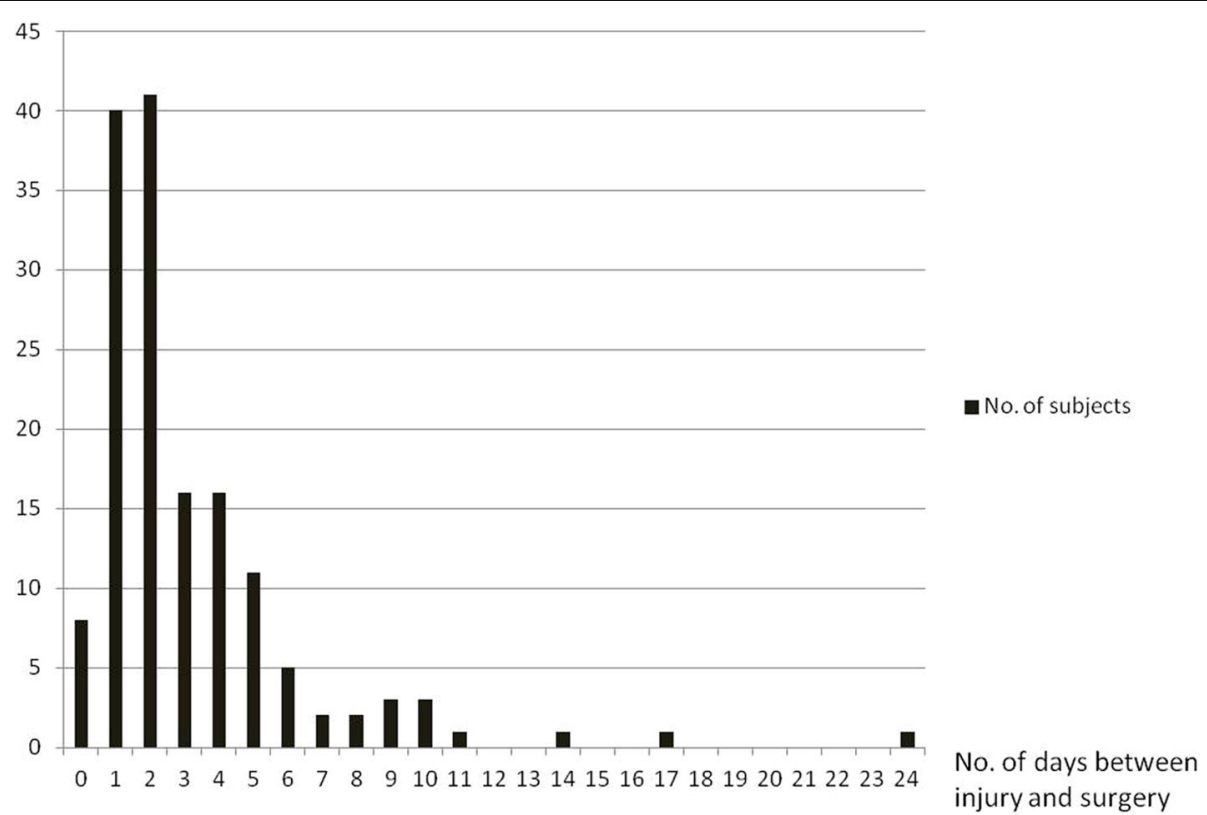

Fig. 2 Distribution of subjects according to the number of days to surgery. A majority of patients (90 of 151, 59.6\%) had a surgical intervention within 2 days of injury. Subjects who had extended delays of surgery all had mitigating medical reason which prevented medical clearance for undergoing surgery 


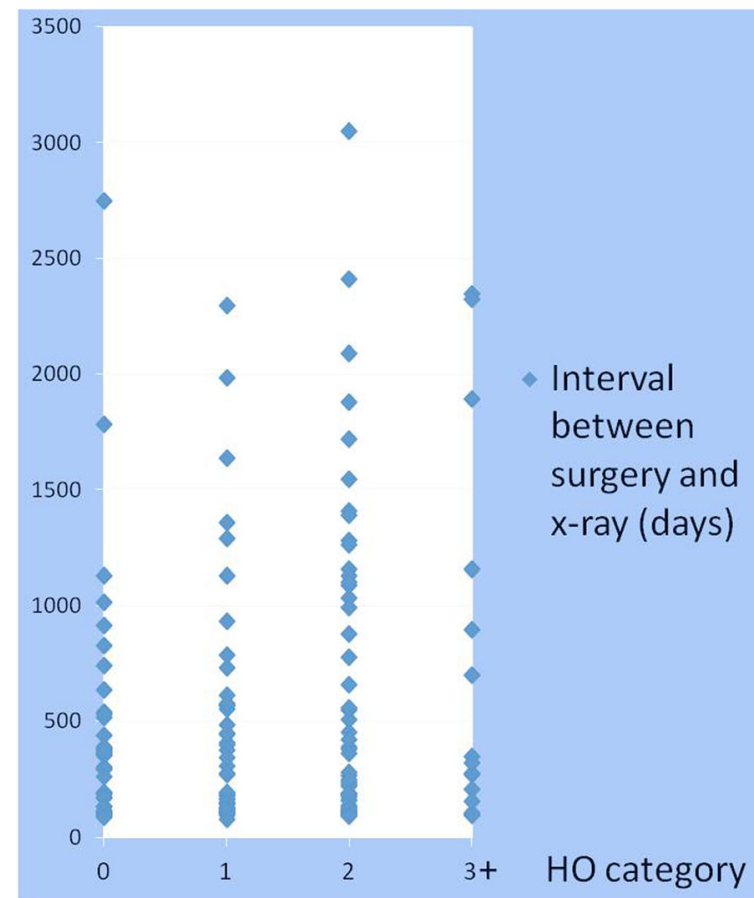

Fig. 3 Distribution of follow-up interval among different $\mathrm{HO}$ categories. The median follow-up interval for class 0 was 353.5 days (range, 89-2746); class 1 was 306 days (range, 76-2296); class 2 was 279 days (range, 94-3049); and class 3+ was 321 days (range, 95-2345). Thus, shortest median follow-up interval was observed with class $2 \mathrm{HO}$ group, and the median follow-up interval was actually shorter for class $3+$ group compared to class 0 group

injury) had higher incidence of $\mathrm{HO}$ compared to those who underwent 'late' surgery (more than 60 days after injury) [16]. Hong et al. showed that the risk of developing $\mathrm{HO}$ after elbow fracture and surgical fixation increased with time to surgery: using the $\leq 24 \mathrm{~h}$ category as the reference, the $2-7$ days category had an OR of 3.78 (95\%CI, 1.12-12.78; $P=0.033$ ) and the $>7$ days category an OR of 10.62 (95\%CI, 2.96-38.09; $P=0.001)$ [17]. Also, Bauer et al. reported longer time to surgery was a risk factor for the development of $\mathrm{HO}$, with subjects waiting 8 or more days for surgery having 12 times the odds of HO than subjects having surgery within a day of injury [18].These last two studies are in line with the findings of our study. However, exact reason for this finding is yet to be determined, and given mixed literature evidence, it remains to be a controversial issue.

Patient age can be an important factor for severity of $\mathrm{HO}$, as one might consider younger patients to have more tendency for bone formation compared to elderly patients. However, our analysis showed that age is not a statistically significant factor associated with severity of HO. Each HO grade had very similar median age and IQR, as well as age range (grade 0 , min 54 years and max 94 years; grade 1 , min 52 years and max 95 years; grade 2, min 34 years and max 94 years; grade 39 , min 33 years and max 86 years). Upon detailed review of individual patient data, there were three particularly young patients. The patient aged 33 years had grade $4 \mathrm{HO}$, in whom interval between surgery and follow-up radiograph was 1894 days. The patient aged 34 years had grade $2 \mathrm{HO}$ with follow-up interval of 2410 days. The patient aged 37 years had grade $4 \mathrm{HO}$ with follow-up interval of 1159 days. Then, the next youngest patient was aged 50 years, who had grade $2 \mathrm{HO}$. Thus, there were only three 'outliers' in terms of age distribution of our study sample, and two of these three subjects had grade $4 \mathrm{HO}$. This could be related to speculation that young patients may be more likely to get severe $\mathrm{HO}$. However, the number of patients is too small to derive statistically meaningful conclusion regarding these very young patients. For patients aged 50-69 years, there were only grade 0,1 and 2 HO's. The remainder of high grade HO's (class 3 and 4) were only found in patients aged 70 years or older. The oldest age for grade $3 \mathrm{HO}$ was 91 years and that for grade $4 \mathrm{HO}$ was 86 years. Despite all these detailed observations, overall age does not seem to be significant confounding factor for $\mathrm{HO}$ grade severity, as demonstrated by our formal statistical analysis.

We did not adjust the analysis for any demographic factors which were previously reported as possible risk factors (such as gender, surgical approach, ethnicity, etc.), as our samples did not suggest that these were risk factors. Nonetheless, we fit a model that adjusted for gender and surgical approach. The results suggest that after further adjusting for gender and surgical approach, the odds of having $\mathrm{HO}$ class one level higher increases by about $30.2 \%$ for every one-day increase in the days to surgery $(\mathrm{OR}=1.302,95 \% \mathrm{CI}: 1.158-1.463, p<0.0001$.) This is in line with our original findings.

A limitation of our study is that there was a large variation in time interval between the date of surgery and date of follow-up radiograph (range 76-3049 days). However, in our study sample, distribution of follow-up interval among different $\mathrm{HO}$ categories $(0,1,2,3+)$ was similar (Fig. 3). Of note, there were total 50 patients who had radiographic follow-up within 180 days of surgery. Of these patients, 11 patients (22\%) had class $0 \mathrm{HO}, 17$ patients $(34 \%)$ had class $1 \mathrm{HO}, 18$ patients $(36 \%)$ had class $2 \mathrm{HO}, 4$ patients $(8 \%)$ had class $3+\mathrm{HO}$. In contrast, 101 patients had follow-up x-ray longer than 180 days after surgery. Of these patients, 27 patients $(27 \%)$ had class $0 \mathrm{HO}, 26$ patients $(26 \%)$ had class $1 \mathrm{HO}, 37$ patients $(37 \%)$ had class $2 \mathrm{HO}, 11$ patients $(10 \%)$ had class $3+\mathrm{HO}$. Fisher's exact test shows the distribution of $\mathrm{HO}$ class is not significantly different between early and late follow-up groups ( $p$-value $=0.7323)$. Moreover, when only using 101 patients who had follow-up x-ray longer than 180 days after surgery, the estimated odds ratio for 
days to surgery was 1.354 with $95 \%$ CI: $1.159-1.583$ $(p=0.0001)$ or was 1.374 with $95 \% \mathrm{CI}: 1.176-1.606$ $(p<0.0001)$ after further adjusting for gender and surgical approach, which suggested that the odds of having $\mathrm{HO}$ class one level higher increased by about $35.4 \%$ for every one-day increase in the days to surgery. The conclusions are consistent with our original analysis. It is generally thought that $\mathrm{HO}$ increases and to be more manifest during longer-term observation [19]. Our finding does not agree with this common belief, and suggests longer follow-up interval does not necessarily lead to increased severity of $\mathrm{HO}$.

Potential confounders for our study included the use of NSAIDS and radiation therapy for reduction of risk of HO. However, review of medical record of all patients showed that no patients received any prophylactic or therapeutic NSAIDS or radiation during the study period, and thus our study was not affected by these factors. Another potential confounder is the mechanism of injury (high velocity injury vs. low velocity injury). However, in our study sample 148 of 151 patients had hip fractures following a mechanical fall (i.e. low velocity injury) making our sample mostly homogeneous. Three patients had hip fractures following "motor vehicle accidents" according to electronic medical record, but precise circumstance of injury (e.g. what type of accident, speed of collision, etc) was not fully described. One patient had class $2 \mathrm{HO}$ and two patients had class $4 \mathrm{HO}$, but effects of a high velocity injury on $\mathrm{HO}$ severity need to be further evaluated with a larger sample size. Finally, we did not correlate for use of medication other than NSAIDS, severity of trauma or post-operative rehabilitation.

The etiologies for the association between time to surgery and increased severity of $\mathrm{HO}$ remain undetermined. Our analysis has ruled out some plausible risk factors but did not identify the actual causative factor, which needs to be explored in further studies.

\section{Conclusions}

Our study showed class 3 or greater $\mathrm{HO}$ was associated with longer time interval between time of acute hip fracture and surgery (median 6 days) compared to all other groups (HO class $0-2)$, which had similar time interval between the fracture and surgery (median 2 days). While it is not always possible, every possible effort should be made to minimize the delay in surgery to reduce the degree of $\mathrm{HO}$.

\section{Abbreviations \\ HO: Heterotopic ossification; ORIF: Open reduction and internal fixation; THA: Total arthroplasty}

\section{Acknowledgements}

Authors would like to thank the following individuals for their contributions to this study but not fulfilling the criteria for authorship: Mathew Teng, MD, for radiographic analysis, and Brian Campfield, MD, for clinical data acquisition.

\section{Consent to publication}

Not applicable.

\section{Author contributions}

$\mathrm{DH}, \mathrm{ESG}, \mathrm{CH}, \mathrm{DEK}$, JN, JY designed this study. ESG performed radiographic analysis. MM performed review of electronic patient record. DLC collected clinical data related to the surgical procedures. JN performed surgeries. $\mathrm{DH}$, ESG, CH, JY, CZ performed data analysis and interpretation. DH, ESG and CH prepared the manuscript, tables, and figures. All authors have read and approved the final manuscript.

\section{Funding \\ No funding was received for this study.}

\section{Availability of data and materials}

The dataset supporting the conclusions of this article is proprietary to Stony Brook University Hospital and will not be shared, because the hospital restricts sharing of the raw data with concerned personnel only. For permission to access the data, contact Department of Radiology, Stony Brook Medicine, HSC 4-120, Stony Brook, NY 11794, USA.

Ethics approval and consent to participate

Our retrospective study received Institutional Review Board approval and the need for informed consent from the patients was waived.

\section{Competing interests}

ESG is a Consultant to Endo Pharmaceuticals Inc. DH is a Section Editor of BMC Musculoskeletal Disorders journal. All other authors report nothing to disclose.

\section{Author details}

'Department of Radiology, Stony Brook Medicine, HSC 4-120, Stony Brook, NY 11794, USA. '2Department of Radiology, University of Colorado School of Medicine, Aurora, CO, USA. ${ }^{3}$ Yale School of Medicine, New Haven, CT, USA. ${ }^{4}$ Department of Orthopedics, Stony Brook Medicine, Stony Brook, NY, USA. ${ }^{5}$ Department of Family, Population and Preventive Medicine, Stony Brook University, Stony Brook, NY, USA. ${ }^{6}$ Department of Applied Mathematics and Statistics, Stony Brook University, Stony Brook, USA

Received: 1 May 2019 Accepted: 17 July 2019

Published online: 27 July 2019

\section{References}

1. Kutzner KP, Hechtner M, Pfeil D, Rehbein P, Kovacevic MP, Schneider M, et al. Incidence of heterotopic ossification in minimally invasive short-stem THA using the modified anterolateral approach. Hip Int. 2017;27(2):162-8.

2. Pohl F, Seufert J, Tausher A, Lehmann H, Springorum HW, Flentje M, et al. The influence of heterotopic ossification on functional status of hip joint following total hip arthroplasty. Strahlenther Onkol. 2005;181(8):529-33.

3. Koelbl O, Seufert J, Pohl F, Tauscher A, Lehmann H, Springorum HW, et al. Preoperative irradiation for prevention of heterotopic ossification following prosthetic total hip replacement results of a prospective study in 462 hips. Strahlenther Onkol. 2003;179(11):767-73.

4. Pakos EE, loannidis JP. Radiotherapy vs. nonsteroidal anti-inflammatory drugs for the prevention of heterotopic ossification after major hip procedures: a meta-analysis of randomized trials. Int J Radiat Oncol Biol Phys. 2004;60(3):888-95.

5. Kan SL, Yang B, Ning GZ, Chen LX, Li YL, Gao SJ, et al. Nonsteroidal antiinflammatory drugs as prophylaxis for heterotopic ossification after total hip arthroplasty: a systematic review and meta-analysis. Medicine (Baltimore). 2015;94(18):e828.

6. Rath E, Warschawski Y, Maman E, Dolkart O, Sharfman ZT, Salai M, et al. Selective COX-2 inhibitors significantly reduce the occurrence of heterotopic ossification after hip arthroscopic surgery. Am J Sports Med. 2016:44(3):677-81.

7. Pavlou G, Salhab M, Murugesan L, Jallad S, Petsatodis G, West R, et al. Risk factors for heterotopic ossification in primary total hip arthroplasty. Hip Int 2012;22(1):50-5

8. Hurlimann M, Schiapparelli FF, Rotigliano N, Testa E, Amsler F, Hirschmann MT. Influence of surgical approach on heterotopic ossification after total hip arthroplasty - is minimal invasive better? A case control study. BMC Musculoskelet Disord. 2017;18(1):27. 
9. Newman EA, Holst DC, Bracey DN, Russell GB, Lang JE. Incidence of heterotopic ossification in direct anterior vs posterior approach to total hip arthroplasty: a retrospective radiographic review. Int Orthop. 2016;40(9):1967-73.

10. Beckmann JT, Wyie JD, Kapron A, Hanson JA, Maak TG, Aoki SK. The effect of NSAID prophylaxis and operative variables on heterotopic ossification after hip arthroscopy. Am J Sports Med. 2014;42(6):1359-64.

11. Davis G, Patel RP, Tan TL, Alijanipour P, Naik TU, Parvizi J. Ethnic differences in heterotopic ossification following total hip arthroplasty. Bone Joint J. 2016;98-B(6):761-6

12. Thilak J, Panakkal JJ, Kim TY, Goodman SM, Lee SS, Salvati EA. Risk factors for heterotopic ossification following total hip arthroplasty in patients with ankylosing spondylitis. J Arthroplast. 2015;30(12):2304-7.

13. Ashton LA, Bruce W, Goldberg J, Walsh W. Prevention of heterotopic bone formation in high risk patients post-total hip arthroplasty. J Orthop Surg (Hong Kong). 2000:8(2):53-7.

14. Brooker AF, Bowerman JW, Robinson RA, Riley LH Jr. Ectopic ossification following total hip replacement: incidence and a method of classification. J Bone Joint Surg Am. 1973;55(8):1629-32

15. d'Heurle A, Archdeacon MT, Hiratzka S, Casstevens C, Finnan R, McCoy B. Do surrogates of injury severity influence the occurrence of heterotopic ossification in fractures of the acetabulum? J Orthop Trauma. 2016;30(4):213-6.

16. Chemaly O, Hebert-Davies J, Rouleau DM, Benoit B, Laflamme GY. Heterotopic ossification following total hip replacement for acetabular fractures. Bone Joint J. 2013;95-B(1):95-100.

17. Hong CC, Nashi N, Hey HW, Chee YH, Murphy D. Clinically relevant heterotopic ossification after elbow fracture surgery: a risk factors study. Orthop Traumatol Surg Res. 2015;101(2):209-13.

18. Bauer AS, Lawson BK, Bliss RL, Dyer GS. Risk factors for post-traumatic heterotopic ossification of the elbow: case-control study. J Hand Surg Am. 2012;37(7):1422-9 e1-6.

19. Lindholm TS, Viljakka T, Vankka E, Popov L, Lindholm TC. Development of heterotopic ossification around the hip. Arch Orthop Trauma Surg. 1986; 105(5):263-7.

\section{Publisher's Note}

Springer Nature remains neutral with regard to jurisdictional claims in published maps and institutional affiliations.

Ready to submit your research? Choose BMC and benefit from:

- fast, convenient online submission

- thorough peer review by experienced researchers in your field

- rapid publication on acceptance

- support for research data, including large and complex data types

- gold Open Access which fosters wider collaboration and increased citations

- maximum visibility for your research: over $100 \mathrm{M}$ website views per year

At $\mathrm{BMC}$, research is always in progress.

Learn more biomedcentral.com/submissions 